\title{
LETTER TO EDITOR
AN INTRODUCTION TO AKUATROP RESEARCH PROGRAMMES
}

\author{
MARINA HASSAN*, NORAINY MOHD HUSIN, LIEW HON JUNG AND NOR AZMAN \\ KASAN
}

Institute of Tropical Aquaculture and Fisheries, Universiti Malaysia Terengganu, 21030 Kuala Nerus, Terengganu, Malaysia.

*Corresponding author: marina@umt.edu.my

Submitted final draft: 9 April $2020 \quad$ Accepted: 25 April 2020

http://doi.org/10.46754/jssm.2020.07.001

\begin{abstract}
The Institute of Tropical Aquaculture and Fisheries is a research institute focusing on research in developing aquaculture-relevant innovations and creating sustainable aquaculture and fisheries practices. Four programmes are offered, each with a panel of experts who can advise and facilitate aquaculture farmers to address their problems to improve their production. The Institute is also actively collaborating with local and international universities and industries in sharing knowledge and transferring technology.
\end{abstract}

Keywords: Aquaculture, fisheries, programme, industry, farmer.

The Institute of Tropical Aquaculture and Fisheries or known as AKUATROP is a higher institution recognised by the Ministry of Education with research focusing on aquaculture and fisheries in line with the national policy under Food Security. AKUATROP Universiti Malaysia Terengganu (UMT) is well equipped with laboratory and hatchery facilities for grow-out production which allow worldclass research to be performed in developing aquaculture relevant innovations to meet the needs of the industries and in creating sustainable aquaculture practices that will improve community livelihood and conserve the environment. With international recognition, AKUATROP is actively collaborating with national and international research institutions, universities, and industries. Apart from conducting research and offering post-graduate programme by research, AKUATROP also provides an attachment programme and special short courses related to aquaculture and fisheries. To further strengthen AKUATROP's foothold in aquaculture and fisheries research, AKUATROP has focused on four major programmes namely breeding technology, green farming technology, aquatic organism health and resources sustainability programme (Figure 1).

Breeding technology is an important key in aquaculture to establish consistent qualitative and quantitative seed production to support market needs and enhance wild-stock populations for sustainable fisheries and aquaculture. Thus, establishing well-designed breeding technology is important to revolutionise conventional seed production method for higher yield quality and maximising profitability. Under the breeding technology programme, AKUATROP leads in crustacean research in marine (swimming crab Portunus sp.; shrimp Penaeus sp.), brackish water (mud crab Scylla sp.) and freshwater (giant prawn Macrobrachium rosenbergii) on their reproductive technology, fundamental biology and physiology, advance research on sexual regulation, disease prevention, nutritional requirement and genetic profile to develop better strain with higher adaptability in line with industry requirement and to enhance natural stock populations through selective breeding programme using microsatellite and DNA sequencing approaches.

Green farming technology is critically important to be implemented in the areas of the proposed aquaculture operation, especially on how water quality is influenced by the anticipated waste loads. Thus, AKUATROP has introduced more research on biofloc. Biofloc technology has recently become an effective and sustainable method to enhance water quality through the addition of extra carbon sources 
into the aquaculture ponds. This is important because this technology can minimise the risks of downstream pollutions where a large quantity of wastes that contain solid forms such as faeces and uneaten feeds can be used by beneficial microbes. Thus the left over waste can settle down in the production pond instead of being released into the environment. We also considered that the environmental impacts have become a concern for the public, various levels of government and aquaculture producers.

Aquatic organism health programme is important in health surveillance, diagnostic and treatment. Diseases in aquaculture are caused by the interactions between the host, the environment, and the presence of pathogen. Infectious diseases are major constraints and challenges for the aquaculture industry. Good management practice is important to prevent losses due to diseases. The uses of improved management practices, movement restrictions, genetically resistant stock, dietary supplements, nonspecific immune-stimulants, probiotics, medicinal plant products, biological control, antimicrobial compounds and water disinfection are the best approaches in controlling the infectious diseases in aquaculture.

Resource sustainability programme aims to ensure the utilisation of natural resources in aquaculture and fisheries are developed sustainably. This programme covers the basic understanding of natural resources particularly species with aquaculture and fisheries importance in terms of biology, ecology, genetics and management. Increasing demand for fish and shellfish has created tremendous pressure on aquatic resources and in many instances some of the aquatic species has been exploited tremendously to the brink of extinction. As such the utilisation and exploitation of aquatic resources should be complementary to sustainable development and conservation of the species. The understanding of these natural resources will help with the management of endangered species including conservation efforts. Under this programme, various field surveys and samples collections are actively carried out for targeted fish and shellfish species including using genetics approach to gain new knowledge that can contribute to utilisation and conservation of the species.

We hope that AKUATROP will be a leader in aquaculture and fisheries research in Malaysia and for other countries. (Appreciation goes to UMT for the continuous support and encouragement in establishing and running all the programmes.)

\section{Acknowledgements}

We would like to thank the Director, Prof Dr Mhd Ikhwanuddin Abdullah, and staff of AKUATROP for their continuous support.

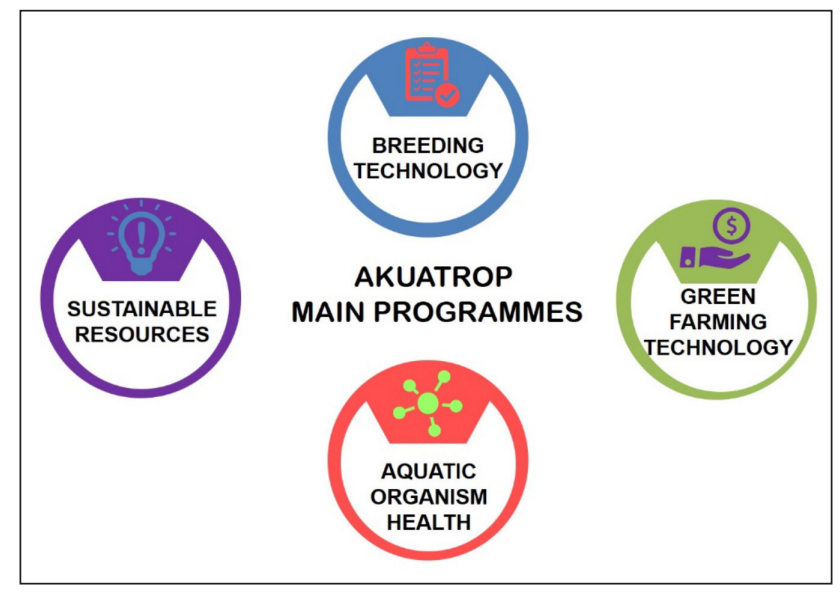

Figure 1: AKUATROP main programmes 